\title{
Correction to: Conceptualizing social entrepreneurship in the context of emerging economies: an integrative review of past research from BRIICS
}

\author{
Subhanjan Sengupta ${ }^{1}$ (D) Arunaditya Sahay ${ }^{1}$. \\ Francesca Croce ${ }^{2}$
}

\section{Correction to: Int Entrep Manag J (2017) https://doi.org/10.1007/s11365-017-0483-2}

The original version of this article unfortunately contained two mistakes.

In Fig. 1: The spelling of Entrepreneurship was wrong, which has been corrected.

In Fig. 6: The content of Drivers was identical as Challenges, which was an error in typing. The drivers are already mentioned in the text as was approved by reviewers. In the figure, the Drives are now mentioned as: (1) Economic Benefits (2) Passion to Bring Change, and (3) Feeling of Ownership.

The online version of the original article can be found at https://oi.org/10.1007/s11365-017-0483-2

Subhanjan Sengupta

subhanjan.sengupta@gmail.com

Arunaditya Sahay

arun.sahay@bimtech.ac.in

Francesca Croce

francesca.croce.1@ulaval.ca

1 Birla Institute of Management Technology, Plot No. 5, Knowledge Park-II, Greater Noida, (NCR), Uttar Pradesh 201306, India

2 Université Laval, 2325 Rue de l’Université, Ville de Québec, QC G1V 0A6, Canada 
The corrected figures are shown below.

The authors regret for the oversight.

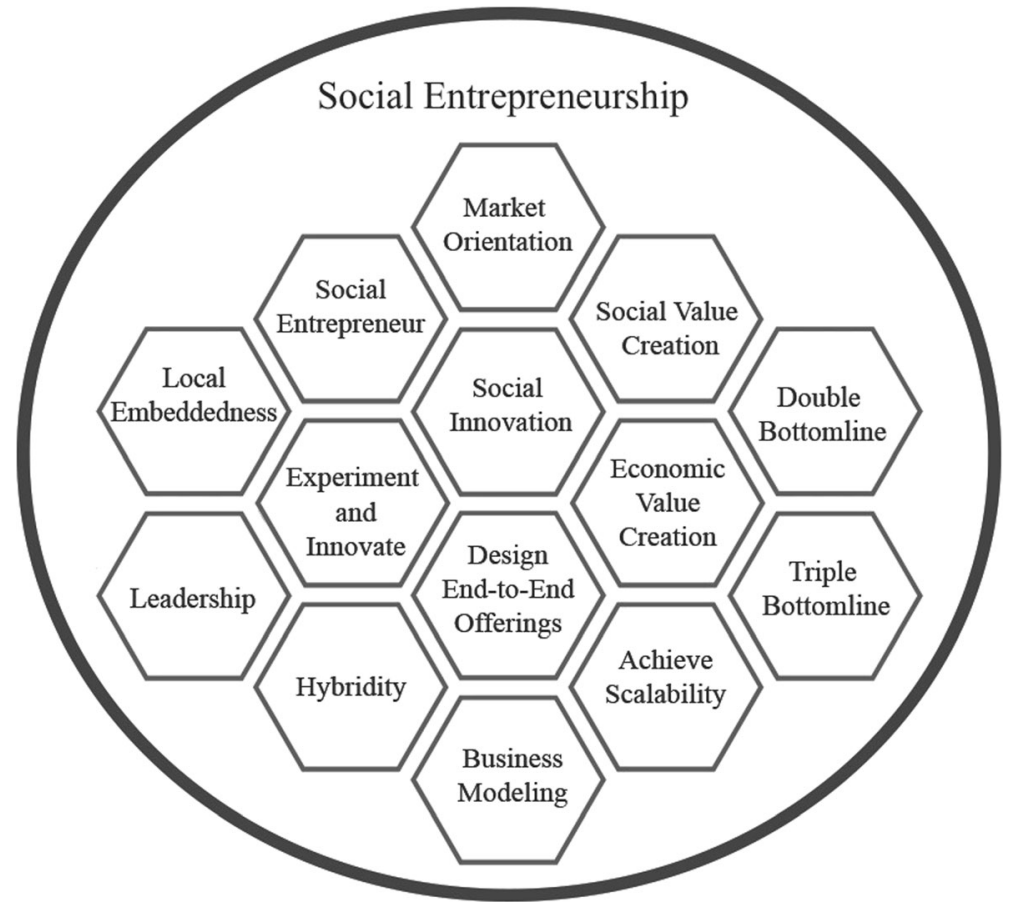

Fig. 1 The Umbrella of Social Entrepreneurship

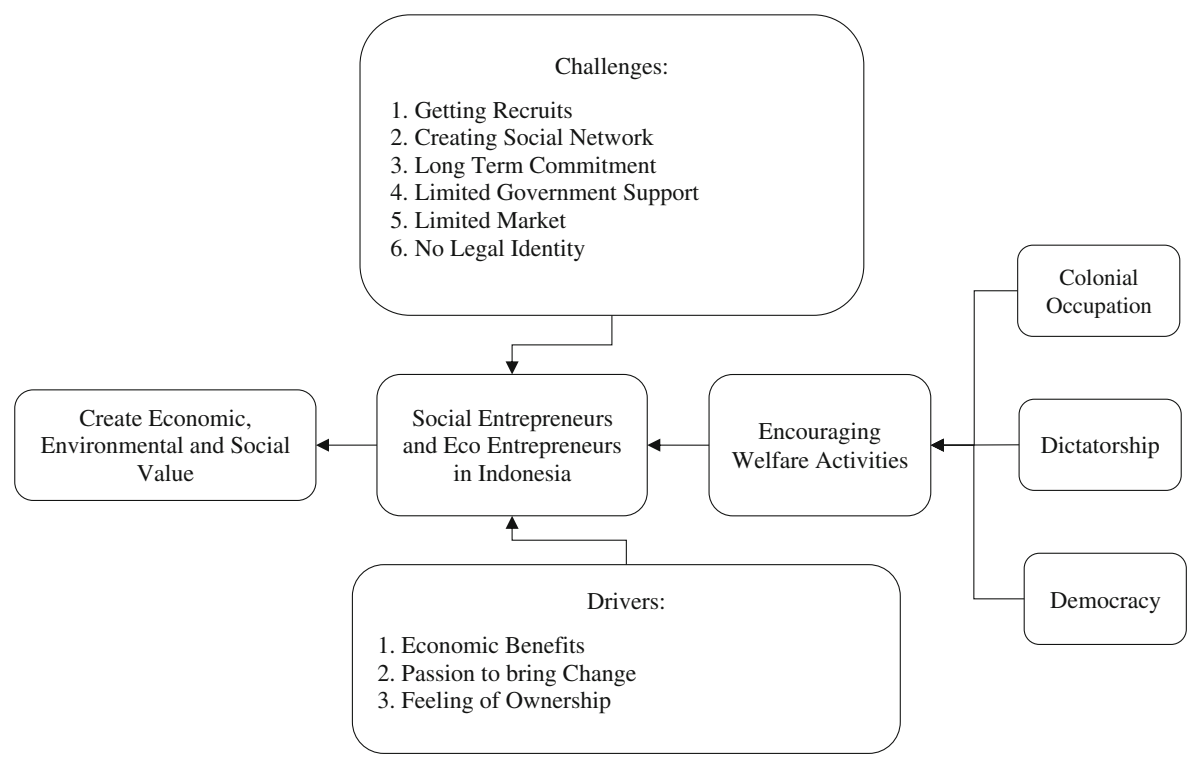

Fig. 6 Social Entrepreneurship in Indonesia 